PTHE UNIVERSITY OF MISSOUNRI ENGINEERING REPRINTA SERIES

Reprint Number 73 $\circ$.

Engineering Experiment Station Columbia, Missouri

\title{
IRROTATIONAL FLOW OVER SPILI
OF FINITE HEIGHT
}

(4) John J. Cassidy, Associate Professor of Civil Engineering

(2) University of Missou

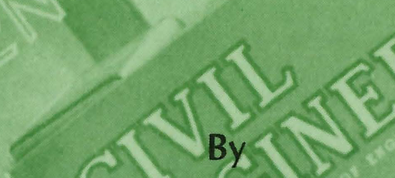

\section{().}

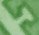




\section{COLLEGE OF ENGINEERING \\ THE ENGINEERING EXPERIMENT STATION}

The Engineering Experiment Station was organized in 1909 as a part of the College of Engineering. The staff of the Station includes all members of the Faculty of the College of Engineering, together with Research Assistants supported by the Station Funds.

The Station is primarily an engineering research institution engaged in the investigation of fundamental engineering problems of general interest, in the improvement of engineering design, and in the development of new industrial processes.

The Station desires particularly to co-operaie with industries of Missouri in the solution of such problems. For this purpose, there is available not only the special equipment belonging to the Station but all of the equipment and facilities of the College of Engineering not in immediate use for class instruction.

Inquiries regarding these matters should be addressed to

The Director

Engineering Experiment Station

University of Missouri

Columbia, Missouri 
Journal of the

ENGINEERING MECHANICS DIVISION

\section{Proceedings of the American Society of Civil Engineers}

\section{IRROTATIONAL FLOW OVER SPILLWAYS OF FINITE HEIGHT}

By John J. Cassidy, ${ }^{1}$ M. ASCE

\section{INTRODUCTION}

Flow over a well-designed spillway generally occurs in an abruptly contracting fashion. Such abruptly contracting flows are understood to be approximately irrotational in nature. 2 Hence, it would seem logical to conclude that if potential theory could be used for the determination of free-surface profiles, discharge coefficients, and pressure distributions, the results would approximate flow over the prototype structure. Two conditions make such a solution particularly difficult for the case of flow over a spillway of finite height and given shape.

1. The elevation of the total-head line is unknown at the outset; and

2 . The velocity at every point on the free surface is a function of the elevation of the point and the location of the total-head line.

Aside from academic interest in overcoming these difficulties, the development of a method of solution is of practical interest. Theoretically, at least, complete control can be maintained over all pertinent variables in an analytic solution, which is, in general, not possible in an experimental study. Comparison of the results of experimental and irrotational-flow studies would make possible a quantitative estimate of the roles of boundary roughness, viscosity, and surface tension.

Apparently, A. Lauck ${ }^{3}$ performed the first solution for free-surface, irrotational flow in a gravitational field. By the simultaneous solution of two integral equations, one derived from the Cauchy integral theorem and one from the Bernoulli equation, Lauck was able to obtain the discharge coefficient and

Note.-Discussion open until May 1, 1966. To extend the closing date one month, a written request must be filed with the Executive Secretary, ASCE. This paper is part of the copyrighted Journal of the Engineering Mechanics Division, Proceedings of the American Society of Civil Engineers, Vol. 91, No. EM6, December, 1965.

1 Assoc. Prof., Dept. of Civ. Engrg., Univ. of Missouri, Columbia, Mo.

2 Rouse, Hunter, "Elementary Mechanics of Fluids, "John Wiley and Sons, New York, N. Y., 1946.

3 Lauck, A., "Ueberfall über ein Wehr," Zeitschrift fur Angewandte Mathematik und Mechanik, Akademie-Verlag GMBH, Berlin, Germany, Vol. 5, 1925. 
coordinates for the free-surface profile produced by flow over an infinitelyhigh weir.

Only a relatively few solutions have been reported since Lauck's 1925 paper and most of these have been described by G. Birkhof $\mathrm{f}^{4}$ and by H. Rouse $\mathrm{H}^{4}$ and S. Garg ${ }^{4}$ in discussions of Birkhoff's paper. No further account of those methods is warranted herein except to note that until 1961, when the writer first began this investigation, no solutions had been obtained for free-surface, irrotational flows over curved shapes of finite height in a gravity field.

Recently, however, two important papers have appeared. T. S. Strelkoff 5 was able to obtain free-surface profiles and discharge coefficients for flow over weirs of finite height, and G. Watters and R. L. Street ${ }^{6}$ have shown freesurface profiles obtained for certain cases of flow over steps and curved humps. Both obtained their solutions by solving integral equations. In Strelkoff's case, the integral equation was derived by means of conformal mapping and the use of distributed singularities; he was able to formulate an algorithm for correction of an initially assumed total head. Watters and Street formulated an integral equation by expressing the complex velocity as an infinite series; they included the Froude number of the downstream flow as an independent variable. However, the shapes of curved flow obstructions apparently cannot be specified independently in either Strelkoff's method or that of Watters and Street.

Because no applicable methods of solution seemed to be available when the writer began this investigation, the study reported herein was conducted for the purpose of developing an analytic method for the determination of discharge coefficients, pressure distributions, and free-surface profiles produced by irrotational flow over a finite-height spillway of specified shape in a gravity field.

Notation. - The symbols used in this paper are defined where they first appear, and are arranged alphabetically in the Appendix.

\section{THE PHYSICAL PICTURE}

A dimensional analysis of the variables involved in flow over a given spillway shape is of considerable aid to understanding. The variables that determine the free-surface profile in such a flow (see Fig. 1) are related as

$$
\mathrm{y}=\phi\left(\mathrm{x}, \mathrm{h}, \mathrm{h}_{\mathrm{D}}, \mathrm{w}, \mathrm{k}, \gamma, \rho, \mu, \sigma, \mathrm{v}_{\mathrm{o}}\right) \ldots \ldots \ldots
$$

in which $\mathrm{y}$ is the vertical coordinate, $\mathrm{x}$ is the horizontal coordinate, $\mathrm{h}$ is the head on the spillway, $\mathrm{h}_{\mathrm{D}}$ describes the spillway shape, $\mathrm{w}$ is the spillway height, $\mathrm{k}$ is a boundary roughness characteristic, $\gamma, \rho, \mu$, and $\sigma$, are the specific weight, density, dynamic viscosity, and surface energy of the fluid respectively, and $\mathrm{V}_{\mathrm{O}}$ is the approach velocity.

4 Birkhoff, G., "Calculation of Potential Flows with Free Streamlines," Journal of the Hydraulics Division, ASCE, Vol. 87, No. HY6, Proc. Paper 2977, November, 1961; with discussion by Hunter Rouse, Vol. 88, No. HY2, Proc. Paper 3087, March, 1962; and S. Garg, Vol. 88, No. HY4, Proc. Paper 3209, July, 1962.

5 Strelkoff, T. S., "Solution of Highly Curvilinear Gravity Flows, " Journal of the Engineering Mechanics Division, ASCE, Vol. 90, No. EM3, Proc. Paper 3950, June, 1964.

6 Watters, G., and Street, R. L., "Two-Dimensional Flow Over Sills in Open Channels," Journal of the Hydraulics Division, ASCE, Vol. 90, No. HY4, Proc. Paper 3967, July, 1964. 
The variable hD is assumed to fully specify the spillway shape. It is obvious that most complex shapes could not be completely specified by one such variable. However, the standard spillway profile is an excellent example of a complex shape that can be so specified (in that case $h_{D}$ would be the design head). Application of the $\pi$ theorem to Eq. 1 produces

$$
\frac{\mathrm{y}}{\mathrm{h}_{\mathrm{D}}}=\mathrm{f}\left(\frac{\mathrm{x}}{\mathrm{h}_{\mathrm{D}}}, \frac{\mathrm{h}}{\mathrm{h}_{\mathrm{D}}}, \frac{\mathrm{w}}{\mathrm{h}_{\mathrm{D}}}, \frac{\mathrm{k}}{\mathrm{h}_{\mathrm{D}}}, \frac{\mathrm{v}_{\mathrm{o}} \mathrm{h}_{\mathrm{D}} \rho}{\mu}, \frac{\mathrm{v}_{\mathrm{o}}}{\sqrt{\frac{\sigma}{\rho \mathrm{h}_{\mathrm{D}}}}}, \frac{\mathrm{v}_{\mathrm{o}}}{\sqrt{\mathrm{g} \mathrm{h}_{\mathrm{D}}}}\right) \ldots
$$

At the present state of mathematical science it is impossible to determine the exact functional relationship indicated in Eq. 2. Indeed, an experimental investigation involving all the dimensionless parameters in Eq. 2 would not be practicable if only because of time requirements. Theoretical consideration of each of the parameters provides the means for simplification of the problem.

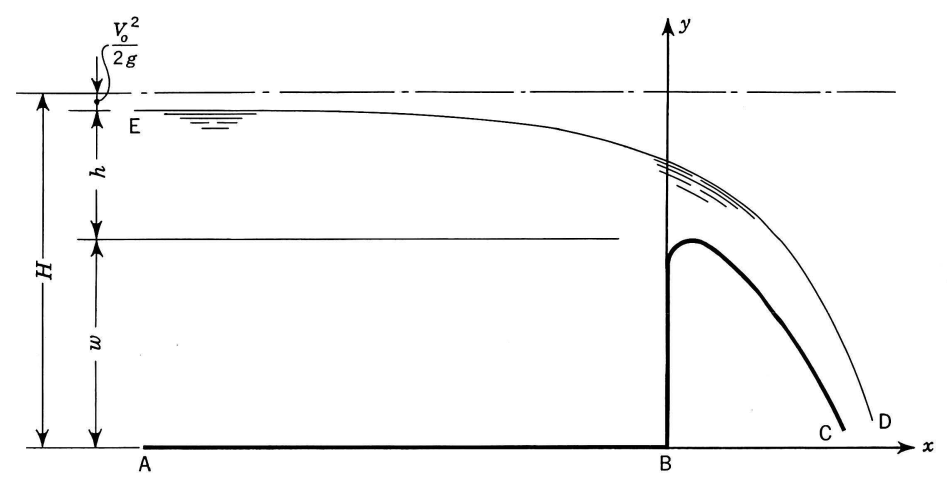

FIG. 1.-FLOW OVER SPILLWAY IN PHYSICAL PLANE

The Reynolds number $\mathrm{V}_{\mathrm{O}} \mathrm{h}_{\mathrm{D}} \rho / \mu$ and the relative roughness $\mathrm{k} / \mathrm{h}_{\mathrm{D}}$ play similar roles and can be considered simultaneously. Viscosity requires that the velocity of the fluid in contact with the boundary be zero, and, hence, a boundary layer exists at the solid boundary. The free surface is displaced outward a distance equal to the displacement thickness. Because the resulting velocity profile places the high-velocity fluid in an advantageous position to pass over the spillway, the discharge coefficient would tend to be increased above the inviscid case. However, viscosity also produces energy dissipation and a resulting slope in the total-head line. A single total-head measurement well upstream, thus, will not indicate the total-head at the spillway. As a result of the energy dissipation, the discharge coefficient would tend to be decreased. Roughness acts to increase both the displacement thickness and energy dissipation rate. Thus, viscosity and the roughness each produces two separate effects that tend to be mutually compensating. However, the degree of compensation is unknown.

The effects of surface energy, as embodied in the Weber number $\mathrm{V}_{\mathrm{o}} /$ $\sqrt{\sigma / \rho \mathrm{hD}}$, can safely be neglected provided the investigation is limited to large scales where pressure differences across curved interfaces are small. 
The role of the Froude number $\mathrm{V}_{\mathrm{O}} / \sqrt{\mathrm{g} \mathrm{h}_{\mathrm{D}}}$ is dependent on whether the approaching flow is rapid or tranquil. For upstream Froude numbers less than unity, $h / h_{D}$ and the Froude number cannot be expressed independently because the discharge coefficient, and, hence, the Froude number as well, will be a unique function of the spillway shape and the head. A solution for the free-surface profile under such conditions must then simultaneously yield a value for the discharge coefficient. If the upstream Froude $n u m b e r$ is greater than unity the control section is upstream from the spillway and the discharge coefficient becomes an independent variable.

If viscosity, surface energy, and boundary roughness are neglected and the investigation is confined to the case of subcritical approaching flow, Eq. 2 becomes

$$
\mathrm{f}\left(\frac{\mathrm{y}}{\mathrm{h}_{\mathrm{D}}}, \frac{\mathrm{x}}{\mathrm{h}_{\mathrm{D}}}, \frac{\mathrm{w}}{\mathrm{h}_{\mathrm{D}}}, \frac{\mathrm{h}}{\mathrm{h}_{\mathrm{D}}}\right)=0 \ldots \ldots \ldots \ldots
$$

Surface profiles and discharge coefficients obtained by investigation of the functional relationship indicated in Eq. 3 could well be expected to be valid for flow at large Reynolds numbers over smooth boundaries of large spillways.

\section{MATHEMATICAL ANALYSIS}

If it is assumed that the entire flow field is irrotational, Eq. 3 is applicable, and the classical methods of potential theory may be used in the analytical investigation of the flow pattern.

The region between the solid boundary and the free surface, as shown in Fig. 1, can be mapped into the complex-potential plane shown in Fig. 2, in which $\phi$ and $\psi$ are the velocity potential and the stream function, respectively. For any given spillway, $\mathrm{h} / \mathrm{h}_{\mathrm{D}}, \mathrm{w} / \mathrm{h}_{\mathrm{D}}$, and the configuration of the solid boundary are known. Because $\mathrm{y}=\mathrm{y}(\mathrm{x})$ is known on the solid boundary, the angle of inclination of the velocity vector can be determined for any point except the stagnation point $B$.

The complex velocity can be written as

$$
\frac{\mathrm{dW}}{\mathrm{dz}}=\mathrm{V} \mathrm{e}^{-\mathrm{i} \theta} \ldots \ldots \ldots \ldots \ldots \ldots
$$

in which $\mathrm{W}$ and $\mathrm{z}=\mathrm{x}+\mathrm{ly}$ refer to the complex-potential and the physical planes, respectively, $\mathrm{V}=$ the magnitude of the velocity vector, and $\theta=$ its inclination. Then the natural logarithm of $\mathrm{dW} / \mathrm{dz}$ is

$$
\ln \left(\frac{d W}{d z}\right)=\ln (V)-i \theta \ldots \ldots \ldots \ldots
$$

Because the geometry is somewhat complicated in the physical plane, it is desirable to work in the complex-potential plane which is always rectangular. A solution to the problem requires that $\mathrm{V}, \theta, \mathrm{x}$, and $\mathrm{y}$ be known as functions of $\phi$ and $\psi$. Because $\ln (\mathrm{V})$ and $\theta$ are harmonic everywhere except where $\mathrm{V}=0, \ln (\mathrm{V})$ and $\theta$ must satisfy the Laplace equation,

$$
\frac{\partial^{2} \ln (\mathrm{V})}{\partial \psi^{2}}+\frac{\partial^{2} \ln (\mathrm{V})}{\partial \phi^{2}}=0 \ldots \ldots \ldots \ldots
$$


and

$$
\frac{\partial^{2} \theta}{\partial \psi^{2}}+\frac{\partial^{2} \theta}{\partial \phi^{2}}=0
$$

A connection between $\ln (\mathrm{V})$ and $\theta$ is provided by the Cauchy-Riemann equations

and

$$
\begin{aligned}
& \frac{\partial \ln (\mathrm{V})}{\partial \phi}=-\frac{\partial \theta}{\partial \psi} \ldots \ldots \ldots \ldots \ldots \ldots \ldots \ldots \ldots \ldots \ldots \\
& \frac{\partial \ln (\mathrm{V})}{\partial \psi}=-\frac{\partial \theta}{\partial \phi} \quad \ldots \ldots \ldots \ldots \ldots \ldots
\end{aligned}
$$

Equations 6, 7, 8, and 9 provide necessary relations hips between the magnitude of the velocity vector and its inclination in the $\mathrm{W}$-plane, but a connection between the complex-potential plane and the physical plane is also required. This connection can be formulated after consideration of the ex-

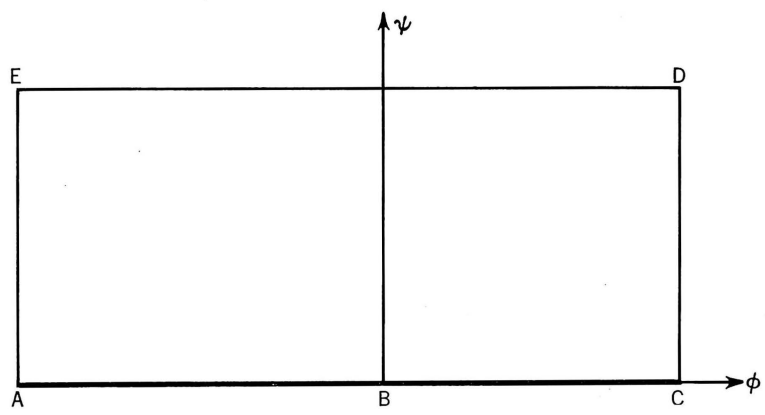

FIG. 2.-COMPLEX-POTENTIAL PLANE

pressions for the stream function and the velocity potential. Because both are functions of $\mathrm{y}$ and $\mathrm{x}$, their total derivatives may be written as

and

$$
\begin{aligned}
& d \psi=\frac{\partial \psi^{\prime}}{\partial x} d x+\frac{\partial \psi}{\partial y} d y \ldots \ldots \ldots \ldots . \ldots \ldots \\
& \mathrm{d} \phi=\frac{\partial \phi}{\partial \mathrm{x}} \mathrm{dx}+\frac{\partial \phi}{\partial \mathrm{y}} \mathrm{dy} \ldots \ldots \ldots \ldots \ldots \ldots \ldots(11)
\end{aligned}
$$

Substituting the horizontal velocity component $u=-\partial \psi / \partial y=\partial \phi / \partial x$ and the vertical velocity component $\mathrm{v}=\partial \phi / \partial \mathrm{y}=\partial \psi / \partial \mathrm{x}$ into Eqs. 10 and 11 produces

and

$$
\begin{aligned}
& \mathrm{d} v=-\mathrm{v} d \mathrm{x}+\mathrm{u} d \mathrm{dy} \ldots \ldots \ldots \ldots(12 \mathrm{~A}) \\
& \mathrm{d} \phi=\mathrm{udx}+\mathrm{v} d \mathrm{dy} \ldots \ldots \ldots \ldots(12 \mathrm{f})
\end{aligned}
$$

Eqs. 12 and 13, when solved simultaneously, yield

and

$$
\begin{aligned}
& \mathrm{dx}=\frac{\mathrm{ud} \phi-\mathrm{v} d v}{\mathrm{u}^{2}+\mathrm{v}^{2}} \ldots \ldots \ldots \ldots \ldots \ldots \ldots \ldots(13 \mathrm{a}) \\
& d y=\frac{v d \phi+u d \psi}{u^{2}+v^{2}} \text {. }
\end{aligned}
$$


From the definition of the velocity vector, $\mathrm{u}=\mathrm{V} \cos \theta$ and $\mathrm{v}=\mathrm{V} \sin \theta$. Thus

and

$$
\begin{aligned}
& \mathrm{dx}=\frac{\cos \theta}{\mathrm{V}} \mathrm{d} \phi-\frac{\sin \theta}{\mathrm{V}} \mathrm{d} \psi \ldots \ldots \ldots \ldots \ldots \\
& \mathrm{dy}=\frac{\sin \theta}{\mathrm{V}} \mathrm{d} \phi+\frac{\cos \theta}{\mathrm{V}} \mathrm{d} \psi \ldots \ldots \ldots \ldots
\end{aligned}
$$

The following derivatives, valid anywhere in the flow field,

and

$$
\begin{aligned}
& \frac{d x}{d \phi}=\frac{\cos \theta}{V}-\frac{\sin \theta}{V} \frac{d \psi}{d \phi} \\
& \frac{d y}{d \phi}=\frac{\sin \theta}{V}+\frac{\cos \theta}{V} \frac{d \psi}{d \phi} \\
& \frac{d x}{d \psi}=\frac{\cos \theta}{V} \frac{d \phi}{d \psi}-\frac{\sin \theta}{V}
\end{aligned}
$$

follow directly from Eqs. 14 and 15.

Finally, the following form of the Bernoulli equation

$$
\frac{\mathrm{v}^{2}}{2 \mathrm{~g}}+\mathrm{y}=\mathrm{H}
$$

must be satisfied along the free surface where the pressure, $p$, is equal to zero. Eqs. 6 through 9 and Eqs. 16 through 20 appear to represent a system of nine equations in seven unknowns. However, only two of Eqs. 6 through 9 are independent because both Eq. 6 and Eq. 7 can be formed by cross-differentiation and addition of Eqs. 8 and 9. Thus, the system is in reality one of seven simultaneous equations involving seven unknowns. To obtain an analytical solution to the problem of irrotational flow over a spillway, this system of equations must be solved according to the proper boundary conditions. Certain mathematical difficulties are to be expected because real solutions to the system of equations need not necessarily exist for all values of the total head, $\mathrm{H}$.

\section{PROCEDURE FOR NUMERICAL SOLUTION}

Numerical procedures and an IBM 7070 digital computer were used to obtain solutions to the for egoing system of equations for three different spillway shapes. To make the solutions as general as possible, dimensionless variables in the following forms were used throughout the analysis and subsequent representation of the results. Thus,

$$
\frac{\mathrm{V}}{\sqrt{2 \mathrm{~g} \mathrm{~h}_{\mathrm{D}}}}, \frac{\psi}{\sqrt{2 \mathrm{~g}} \mathrm{~h}_{\mathrm{D}}^{3 / 2}}, \frac{\phi}{\sqrt{2 \mathrm{~g} \mathrm{~h}_{\mathrm{D}}^{3 / 2}}}, \frac{\mathrm{p}}{\gamma \mathrm{h}_{\mathrm{D}}}, \frac{\mathrm{y}}{\mathrm{h}_{\mathrm{D}}}, \frac{\mathrm{x}}{\mathrm{h}_{\mathrm{D}}}, \frac{\mathrm{H}}{\mathrm{h}_{\mathrm{D}}}, \frac{\mathrm{w}}{\mathrm{h}_{\mathrm{D}}}, \frac{\mathrm{h}}{\mathrm{h}_{\mathrm{D}}}
$$

However, for purposes of simplicity, only the numerators of these dimensionless variables have been used herein to represent the corresponding 
dimensionless forms. The following finite difference equation, derived by W. G. Bickley, ${ }^{7}$ was substituted for Eq. 7 as

$$
20 \theta_{0}=4\left(\theta_{1}+\theta_{2}+\theta_{3}+\theta_{4}\right)+\left(\theta_{5}+\theta_{6}+\theta_{7} \theta_{8}\right) \ldots
$$

Terms of the order $\mathrm{m}^{6}$ have been neglected in Eq. 21. The finite-difference mesh spacing $m$ and the subscripts are defined in Fig. 3. Eqs. 8 and 9 were written in integral form as

$$
\Delta \ln (\mathrm{V})=\int_{\phi_{1}}^{\phi} 2-\frac{\partial \theta}{\partial \psi} \mathrm{d} \phi \ldots \ldots \ldots \ldots
$$

and

$$
\Delta \ln (\mathrm{V})=\int_{\psi_{1}}^{\psi} \frac{\partial \theta}{\partial \phi} \mathrm{d} \psi \ldots \ldots \ldots \ldots
$$

in which $\Delta \ln (\mathrm{V})=$ the change in $\ln (\mathrm{V})$ over the interval of integration.

Eqs. 16, 17, 18, and 19 were expressed in the integral forms

$$
\begin{aligned}
& \Delta \mathrm{x}=\int_{\psi_{1}}^{\psi_{2}}-\frac{\sin \theta}{\mathrm{v}} \mathrm{d} \psi \ldots \ldots \ldots \ldots \\
& \Delta \mathrm{x}=\int_{\phi}^{\phi} 2 \frac{\cos \theta}{\mathrm{v}} \mathrm{d} \phi \ldots \ldots \ldots \ldots \\
& \Delta \mathrm{y}=\int_{\psi_{1}}^{\psi_{2}} \frac{\cos \theta}{\mathrm{V}} \mathrm{d} \psi \ldots \ldots \ldots \ldots \\
& \Delta y=\int_{\phi}^{\phi} 2 \frac{\sin \theta}{\mathrm{V}} \mathrm{d} \phi \quad \ldots \ldots \ldots \ldots \ldots
\end{aligned}
$$

valid only along lines of constant $\phi$ or $\psi$.

As was noted previously, a singularity exists at the stagnation point on the upstream side of the spillway. At this point $\ln (\mathrm{V})$ becomes infinite and $\theta$ becomes undefined. This difficulty was avoided by using the mapping function $\mathrm{W}=\mathrm{z}^{2}$ to represent flow in the corner near the stagnation point.

The numerical procedures were programmed for solution in an iterative fashion. Initially, values of $\theta$ and $\ln (\mathrm{V})$ as functions of $\phi$ and $\psi$ were assumed for all boundaries. Realistic assumptions were made in agreement with a rough flow net drawn for an assumed free surface. To compute initial values for $\ln (\mathrm{V})$, it was necessary to assume an initial value for the total head and, in the course of solution, it was then necessary to improve on the assumed values for both the free-surface coordinates and the total head.

Improvement of the values of $\mathrm{H}, \mathrm{x}(\phi, \psi)$ and $\mathrm{y}(\phi, \psi)$ was accomplished in the following iterative fashion:

7 Bickley, W. G., "Finite-Difference Formulae for the Square Latice," Quarterly Journal of Mechanics and Applied Mathematics, London, England, Vol. 1, Part 1, 1948. 
1. A $\theta(\phi, \psi)$ field was computed in agreement with the assumed values on the boundary by successively applying Eq. 21 to each interior point in the $\mathrm{W}$-plane (a relaxation process).

2. Beginning with values of $\ln (\mathrm{V}(\phi, \psi))$ on the free surface, as determined from velocities obtained by application of the Bernoulli equation, a $\ln (\mathrm{V}(\phi, \psi))$ field was determined in the W-plane through numerical integration of Eqs. 22 and 23.

3. Values for $\mathrm{y}(\phi, \psi)$ or $\mathrm{x}(\phi, \psi)$ were determined for the free surface and the solid boundary using Eqs. 24, 25, 26, and 27. If these values differed from the previously used $\mathrm{y}(\phi, \psi)$ and $\mathrm{x}(\phi, \psi)$ by less than $1.0 \%$, the solution was assumed to be complete.

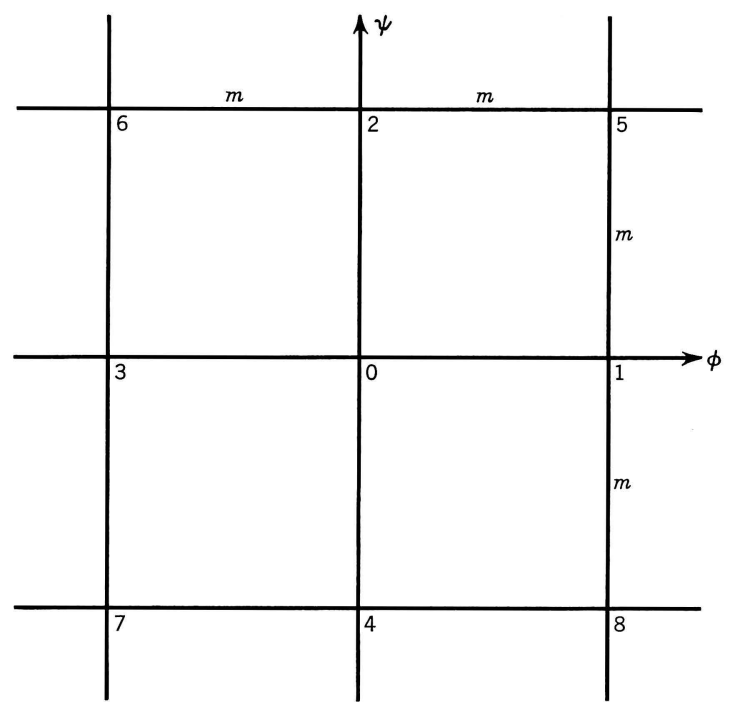

FIG. 3.-FINITE-DIFFERENCE MESH

4. If the values of $\mathrm{x}(\phi, \psi)$ or $\mathrm{y}(\phi, \psi)$ computed in Step 3 differed too greatly from the previously used values, new values of $\theta(\phi, \psi)$ were computed for all boundaries in agreement with the new $\mathrm{x}(\phi, \psi)$ and $\mathrm{y}(\phi, \psi)$. Observation of the behavior of the free-surface coordinates provided an algorithm for the correction of the approximated total head. This correction is explained in greater detail in the following text. After proper adjustment of the total head, values of $\ln (\mathrm{V}(\phi, \psi))$ were computed along the free surface in accordance with the new $\mathrm{y}(\phi, \psi)$ and $\mathrm{H}$.

5. The programmed solution was then cycled back to Step 1 for another iteration. This procedure was continued until $\mathrm{x}(\phi, \psi), \mathrm{y}(\phi, \psi)$, and $\mathrm{H}$ remained constant throughout successive iterations.

As was stated earlier, it was necessary to assume an initial value for the total head. By observing the behavior of the coordinates for the free surface 
profile, it was possible to determine whether the assumed total head was smaller or larger than the correct value. Fig. 4 illustrates the behavior of the free-surface profile with assumed values of the discharge coefficient. When the discharge coefficient was too large (this results in a total head which is also too large), the computed free-surface ordinates became progressively smaller with each succeeding iteration. An opposite trend occurred when the assumed discharge coefficient was too small. When a satisfactory value for the discharge coefficient was assumed, the computed free-surface profile approached a limiting position.

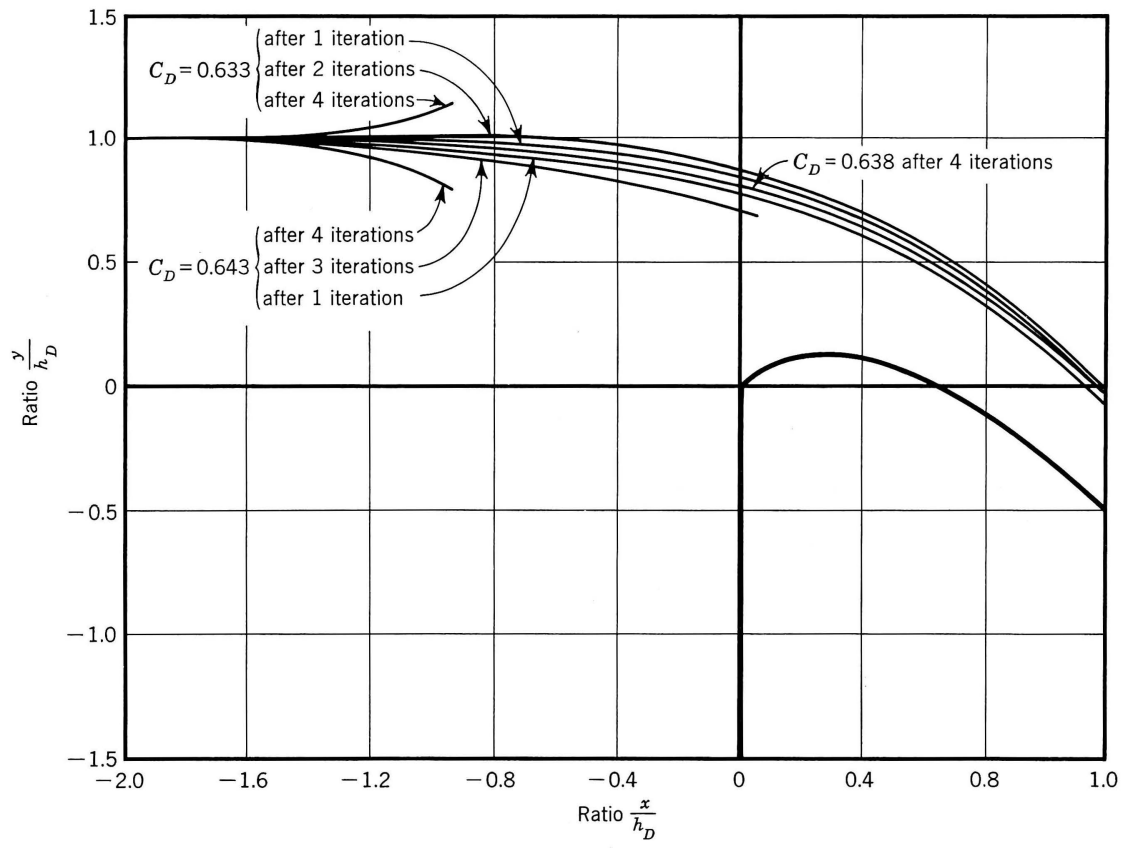

FIG. 4.-BEHAVIOR OF NUMERICALLY-DETERMINED FREE-SURFACE PROFILE WHEN $\mathrm{C}_{\mathrm{D}}$ WAS IN ERROR

Three separate spillway shapes were analyzed in the foregoing manner. The first shape corresponded to that of a standard spillway, whereas the second shape was proportioned according to the nappe produced by flow over a weir subject to a negative pressure head $\Delta / \mathrm{p} \gamma$ beneath the nappe equal to one-half the head on the weir. The third shape was formed by a vertical upstream face, a circular crest, and a plane downstream slope. Each shape was analyzed for flow at several heads. The resulting free-surface profiles and pressure distributions are shown in Figs. 5, 6, and 7 and the final values for the discharge coefficients are shown in Fig. 8.

Accuracy of the numerical procedures was estimated by solving one problem at successively reduced finite-difference intervals (increased number of 


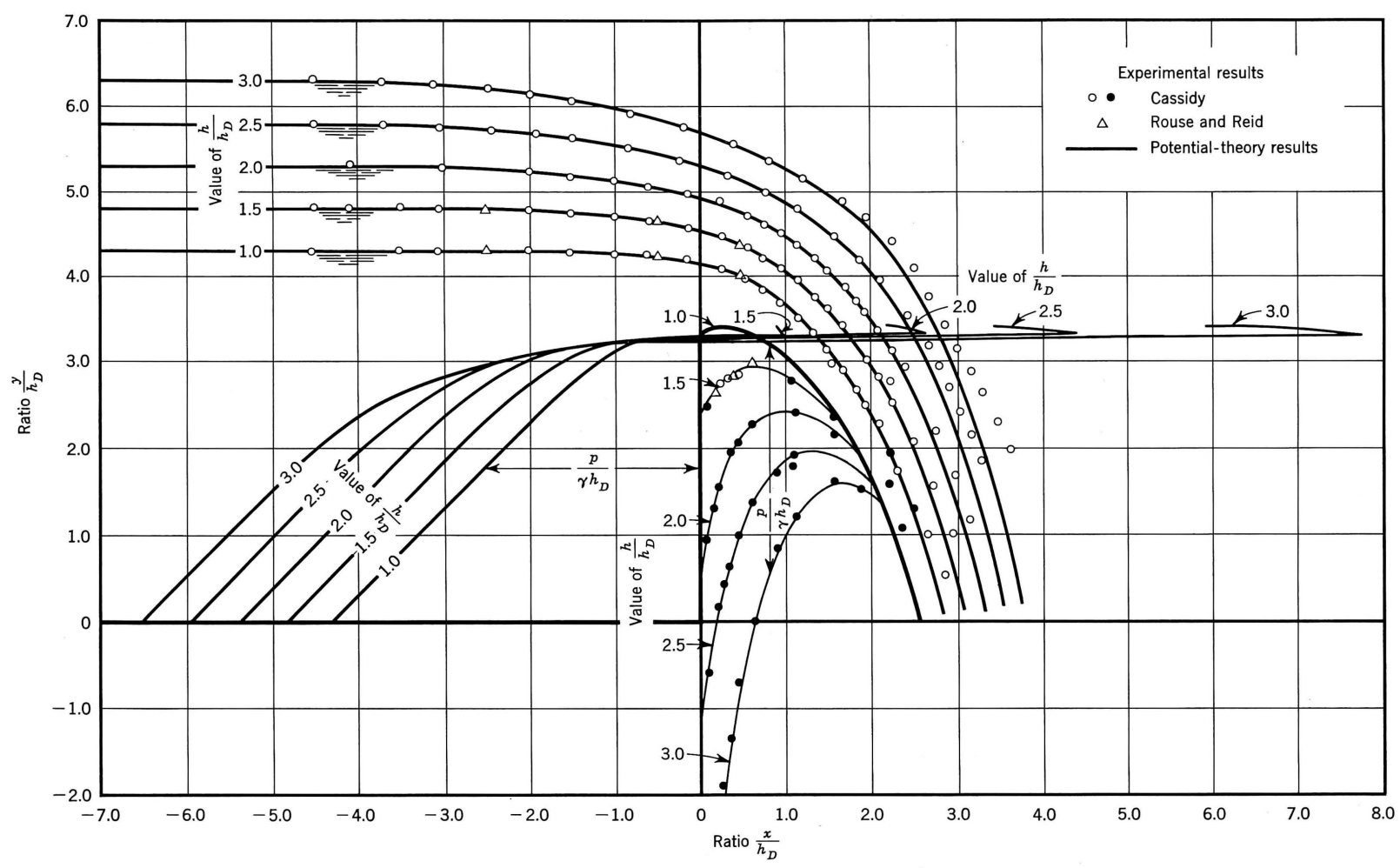




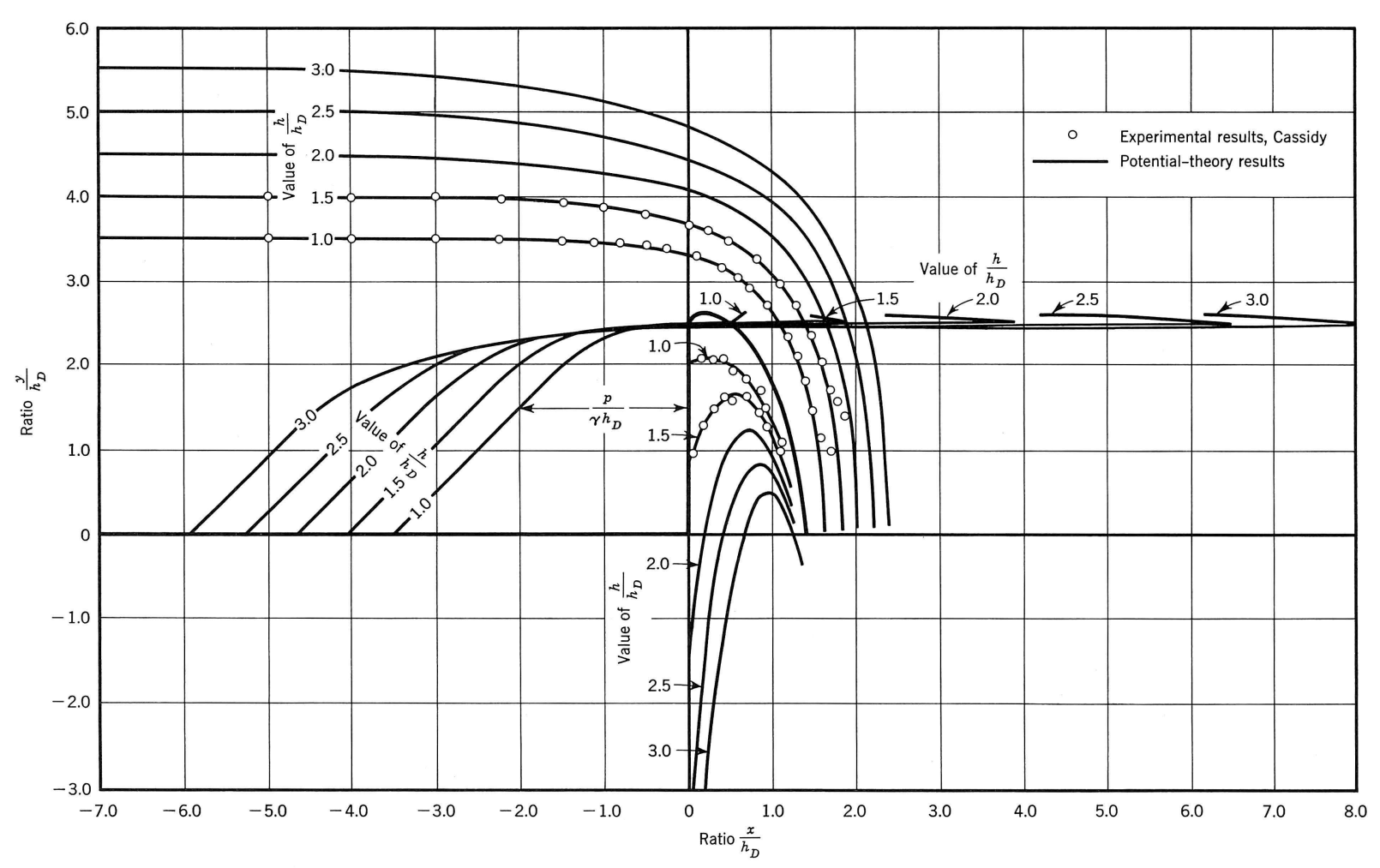




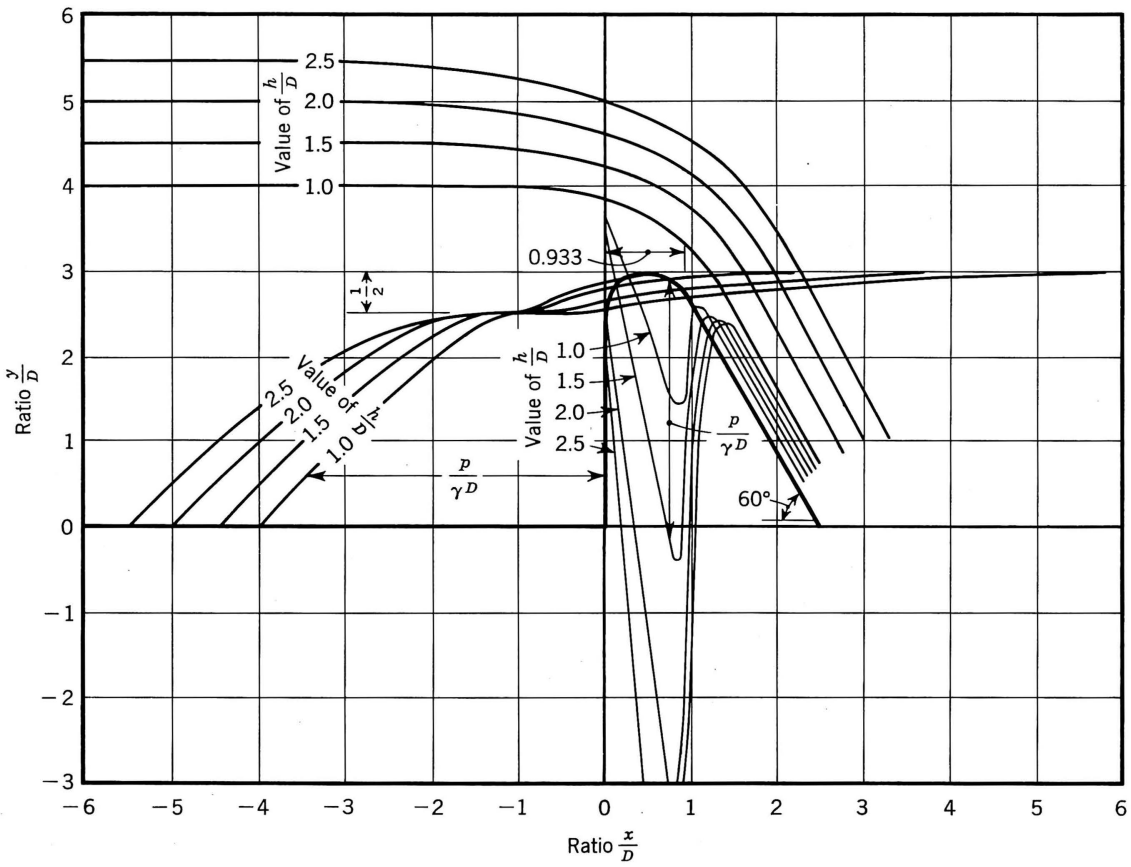

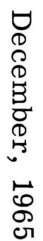

FIG. 7.-FREE-SURF ACE PROFILES AND PRESSURE DISTRIBUTIONS FOR SPILLWAY WITH CIRCULAR CREST 
streamlines). For the standard spillway shape with flow at design head, nineteen streamlines were required to produce $\mathrm{x}$ and $\mathrm{y}$ coordinates that were within $1.0 \%$ of the apparent limiting value. The accuracy of the assumed discharge coefficient also affected the inherent accuracy in the computed co-

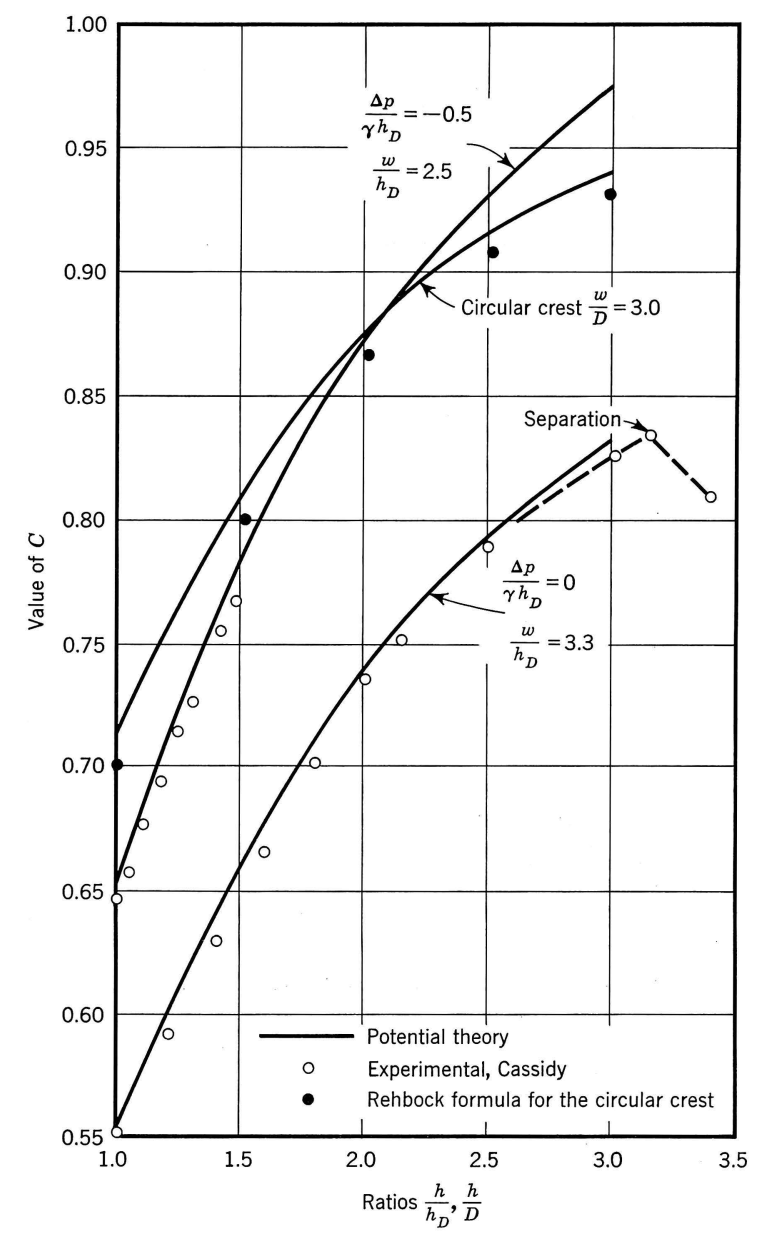

FIG. 8.-DISCHARGE COEFFICIENTS FOR THREE SPILLWAY SHAPES

ordinates. Discharge coefficients within $1.0 \%$ of their apparent limiting values were found to produce the above noted accuracy in coordinates.

Computed free-surface coordinates were also plotted in the fashion shown in Figs. 10, 11, and 12. Observation of these plots indicates an apparent linear relationship between $\mathrm{y}$ and $\mathrm{h}$ for particular values of $\mathrm{x}$. This apparent linear 
property was used to extrapolate free-surface ordinates for particular values of $h$ and $x$ after free-surface profiles had been obtained for two values of $h$. It should be noted that Rouse ${ }^{8}$ has shown a similar apparent linear property for the coordinates of free-surface profiles produced by flow over sharpcrested weirs.

\section{RESULTS}

Free-Surface Profiles. - Two different sets of figures are used to show the computed free-surface coordinates. Fig. 5, 6, and 7 show $\mathrm{x}$ versus $\mathrm{y}$

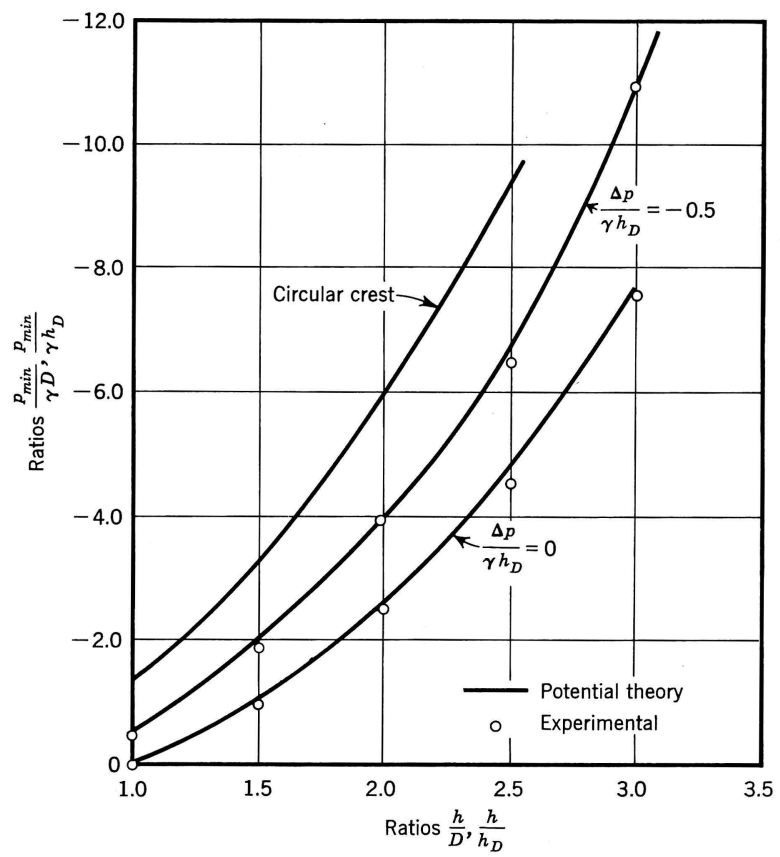

FIG. 9.-MINIMUM PRESSURES FOR THREE SPILLWAY SHAPES

plotted as functions of $\mathrm{h}$ whereas Figs. 10, 11, and 12 show y versus $\mathrm{h}$ plotted as functions of $x$. The diameter, $D$, was used to form the dimensionless parameters describing flow over the circular crest because it was the independent geometric variable. Figs. 5, 6, and 7 provide physical clarity whereas Figs. 10, 11, and 12 illustrate an apparent functional relationship.

8 "Engineering Hydraulics," Edited by Hunter Rouse, John Wiley and Sons Inc., New York, N. Y., 1950. 
Experimental results obtained by $\mathrm{H}$. Rouse and L. Reid 9 and the writer 10 have been plotted on Fig. 5 for the purpose of comparison. The close agreement of the results of experiment and theory indicate that the effects of

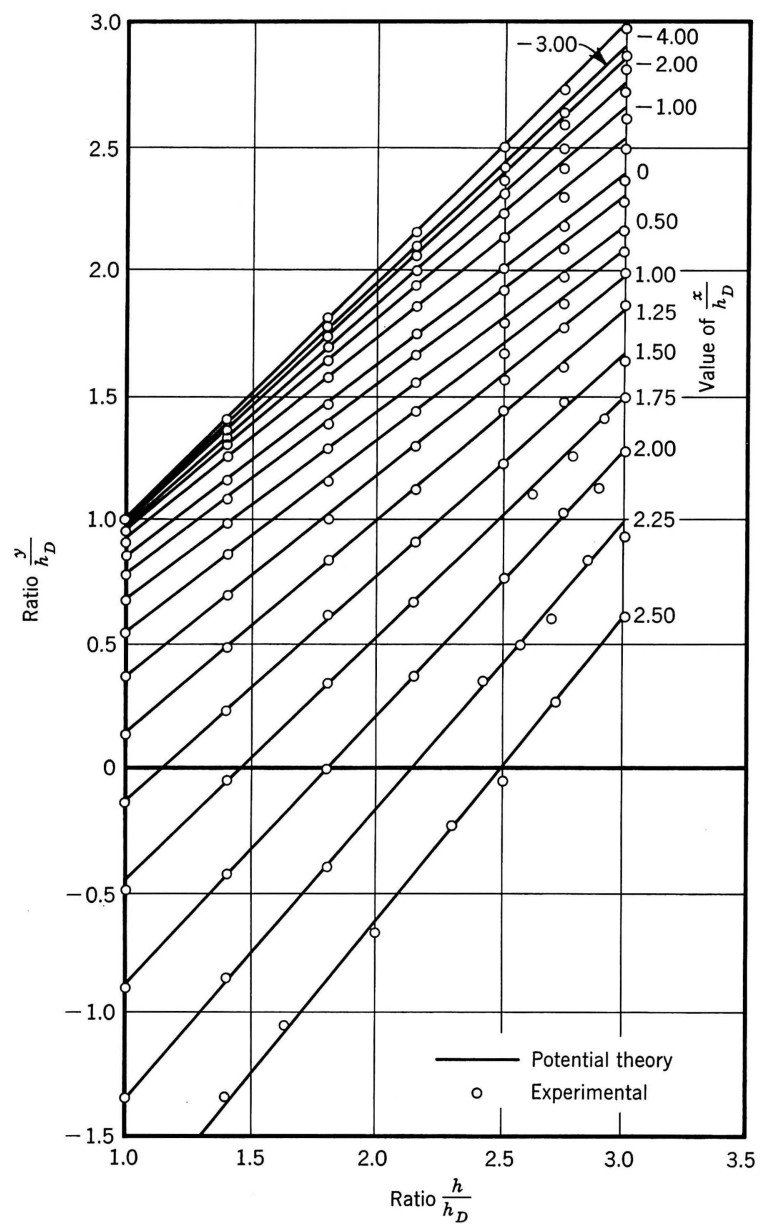

FIG. 10.-FREE-SURFACE COORDINATES FOR STANDARD SPILLWAY $\left(\Delta \mathrm{p} / \gamma \mathrm{h}_{\mathrm{D}}=0.0\right)$

viscosity and surface tension are small with regard to the location of the free-surface profile.

9 Rouse, H., and Reid, L., "Model Research on Spillway Crests, " Civil Engineering, Vol. 5, No. 1, January, 1935.

10 Cassidy, J. J., "Spillway Discharge at Other Than Design Head," thesis presented to the Univ. of Iowa, at Iowa City, Iowa, in June, 1964, in partial fulfilment of the requirements for the degree of Doctor of Philosophy. 
Because of complexity, nothing has been said with regard to the uniqueness of the solutions obtained using the method reported herein. However, the close comparison of experimental and theoretical results serves to indicate that the solutions obtained mathematically were those of interest.

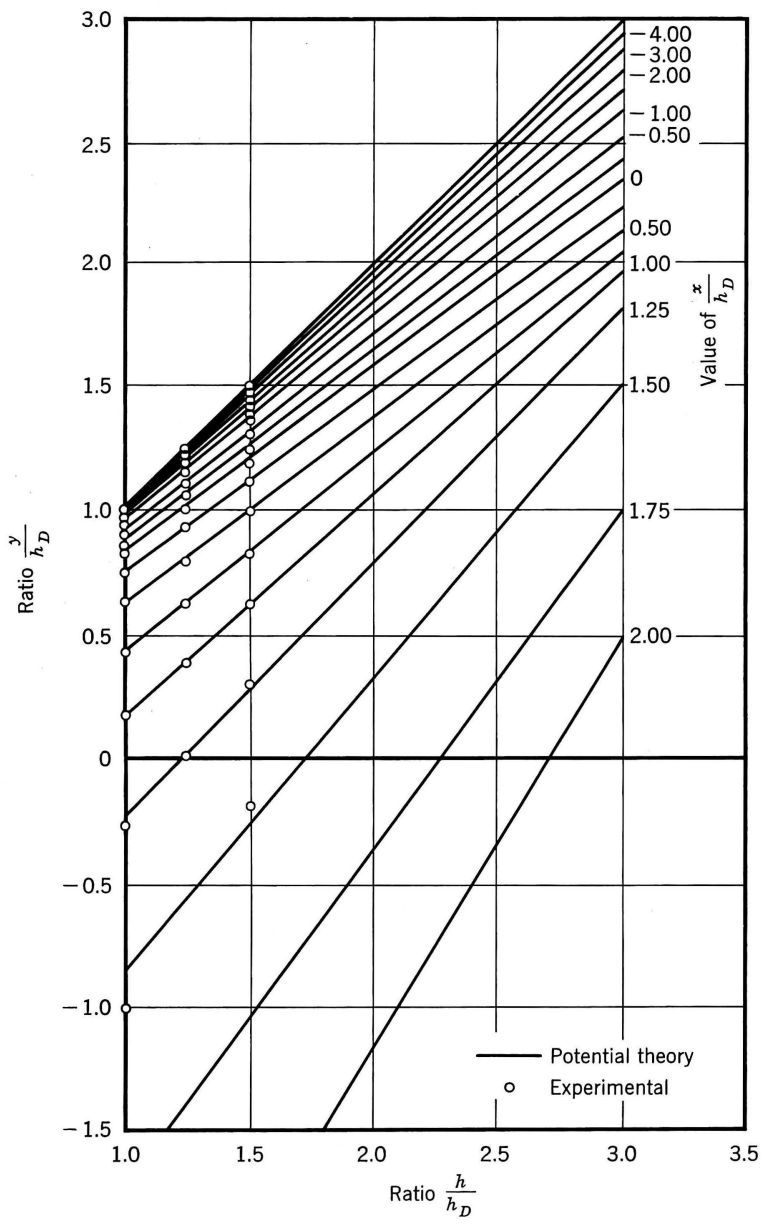

FIG. 11.-FREE-SURFACE COORDINATES FOR SPILLWAY DESIGNED FOR $\Delta \mathrm{p} / \gamma \quad \mathrm{h}_{\mathrm{D}}=-0.5$

Pressure Distributions.-Once the velocity field has been determined, the Bernoulli equation was used to compute dimensionless pressures on the solid boundaries. The resulting pressure distributions are shown in Figs. 5, 6, and 7. For the two spillway shapes patterned after weir nappes, points of minimum pressure are seen to occur at points of maximum boundary curvature. How ever, for the circular crest, the point of minimum pressure is located at the downstream point of tangency. Close agreement between experiment and theory 
is shown in Figs. 5 and 6, but no experimental values were available for comparison with the theoretical results obtained for the circular crest.

Minimum pressures occurring on the face of the spillways are plotted as functions of head in Fig. 9. The pressure magnitudes are seen to decrease rapidly with increasing head. Vapor pressure would be the lower limit of the negative pressures because cavitation would then occur. Another possible lower

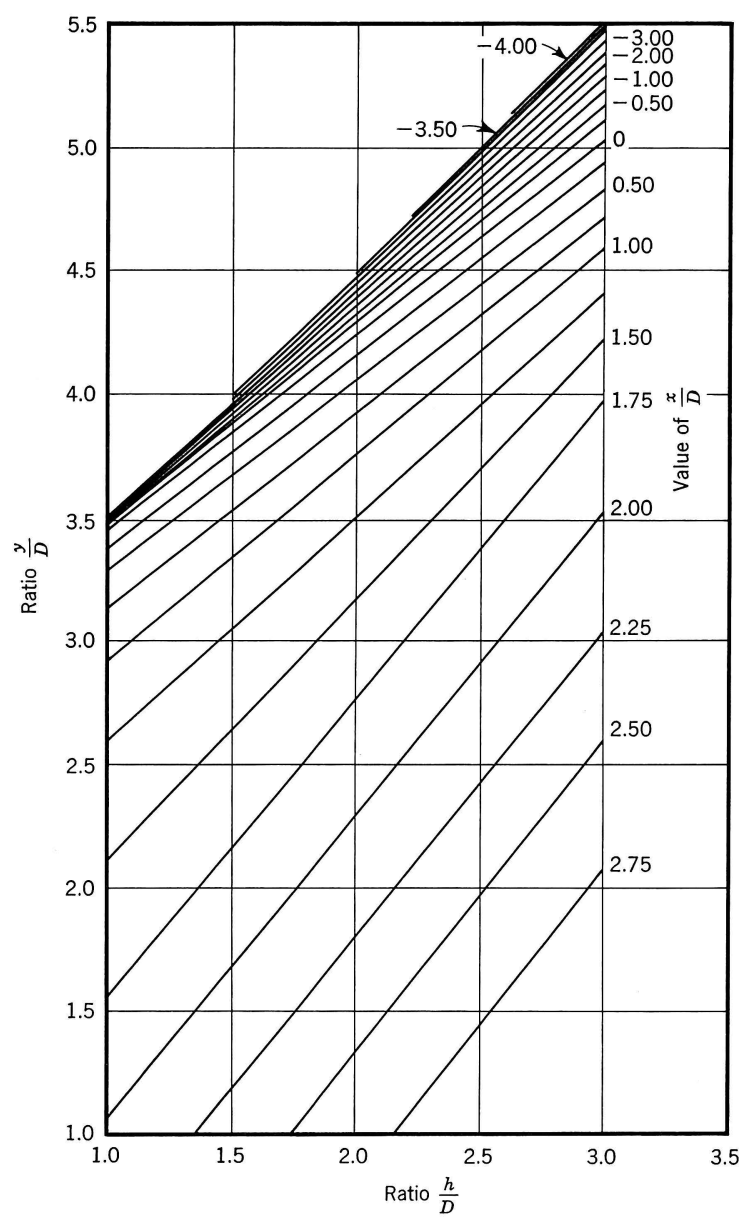

FIG. 12.-FREE-SURFACE COORDINATES FOR SPILLWAY WITH CIRCULAR CREST

limit would be that at which separation of the nappe occurs. However, separation is a boundary-layer phenomenon and cannot be predicted from the consideration of pressure or piezometric head alone. It should be noted that separation on a standard spillway, according to O. Dillman, 11 will occur at a head equal to approximately $3.2 \mathrm{hD}$.

11 Dillman, O., "Untersuchungen an Ueberfallen," Mitteilungen die Hydraulischen Instituts der T. H. Munchen, Oldenbourg, Munich, Germany, No. 7, 1933. 
Discharge Coefficients. - Fig. 8 shows experimental and analytical values of $\mathrm{C}$ as a function of head for each spillway. The analytically determined values are seen to be consistently lower than experimental values indicating that viscosity and surface tension produce a net decrease in the discharge coefficient.

Method of Solution.-A chief disadvantage associated with the method of solution described herein is that of practicability. Large computer storage capacity is a necessity because of the size of the $\ln (\mathrm{V})$ and $\theta$ arrays that must be stored. Approximately $6 \mathrm{hr}$ of operational time were required on the IBM-7070 to obtain a solution for the standard spillway shape. These time and storage requirements necessarily eliminate the use of small computers for all but the simplest of problems.

The major attribute of the method is that of directness; all independent variables are specified in the physical plane making it possible to obtain free-surface profiles, discharge coefficients, and pressure distributions for flow over a particular boundary configuration.

\section{CONCLUSIONS}

In this study, a method was developed for the numerical solution of steady, irrotational, free-surface flow over a continuous lower boundary in a gravitational field. Pressure distributions, velocity distributions, free-surface coordinates, and discharge coefficients can be obtained therewith when all independent variables are specified in the physical plane. Because the method is one of successive approximation, it is a definite improvement over methods wherein the surface is located by trial-and-error procedures. For cases of spillways of finite height and tranquil approaching flow, the total head is initially unknown and cannot be obtained in a direct manner. Through observation of the behavior of the free-surface profile during the solution, an algorithm can be obtained for correcting assumed values of total head. Large computer-storage and long computer-time requirements are distinct disadvantages associated with application of the method. Neither of these disadvantages is as important for solution of problems involving super-critical approaching flow, for which the total head is an independent variable.

As a direct result of the experimental and analytical studies performed, the following conclusions can be drawn with regard to spillway flow characteristics:

1. Free-surface profiles obtained by potential theory and by experiment agree well and indicate that viscosity has a negligible influence on the location of the free surface. However, computed discharge coefficients for irrotational flow are larger than experimentally measured values by a small but noticeable quantity.

2. The location of the points of minimum pressure produced by flow over a spillway at a particular head is dependent on the boundary configuration. For a spillway shaped after weir-nappe profiles, the point of minimum pressure (and hence the point of incipient cavitation) occurs at the point of maximum curvature. For the circular crest used in this study, the minimum pressure occurred at the downstream point of tangency.

3. The curves for minimum pressure on the spillway surface developed in this study can be used to design spillways that will operate without cavitation 
through the entire range of expected heads. Such a design would be more rational than one based on a design head chosen as some fraction of the maximum expected head.

\section{ACKNOWLEDGMENTS}

The study described herein was conducted while the writer was a graduate student in the Department of Mechanics and Hydraulics at the University of Iowa, Iowa City, Iowa. Computer time was donated by the University and all experimental work was performed in the laboratory of the Iowa Institute of Hydraulic Research. The writer is indebted to his advisor, Hunter Rouse, for both the original suggestion of the study and for his advice and encouragement as the study progressed.

\section{APPENDIX. --NOTATION}

The following symbols have been adopted for use in this paper:

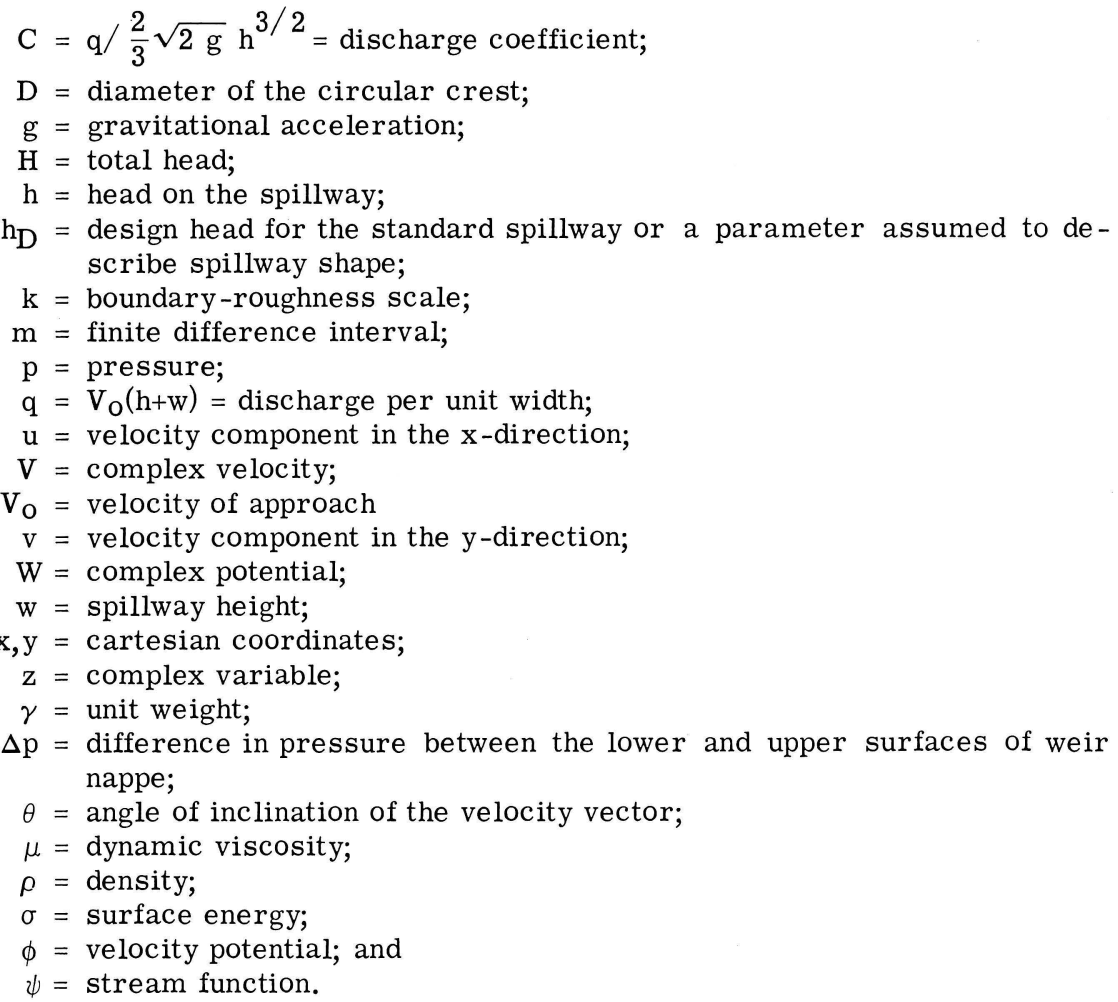






KEY WORDS: coefficients; engineering mechanics; hydraulics; laminar flow; pressure; I spillways; water flow

ABSTRACT: Potential theory is used to analyze free-surface, irrotational flow over spillways of finite height. Numerical values were obtained for free-surface coordinates, , pressures on the surface of the spillway, and discharge coefficients for three separate spillway shapes. The spillways considered included (a) one corresponding to the shape of the nappe produced by flow over a ventilated, sharp-crested weir, (b) one corresponding to the shape of the nappe produced by flow over a ventilated, sharp-crested weir with nagative pressure head beneath the nappe equal to one-half the head on the weir, and (c) one having vertical upstream face, a cylindrical crest, and a downstream I tangent inclined $30^{\circ}$ from the vertical. Because flows of several heads were analyzed for each spillway, certain conclusions were drawn relative to spillway operation under high heads.

REFERENCE: Cassidy, John J., “Irrotational Flow Over Spillways of Finite Height," Journal of the Engineering Mechanics Division, ASCE, Vol. 91, No. EM6, Proc. Paper 4591, December, 1965, pp. 155-173. 


\section{PUBLICATIONS OF THE ENGINEERING REPRINT SERIES}

Copies of publications may be secured from the Director of the Engineering Experiment Station, University of Missouri. Single copies may be obtained free unless otherwise indicated until the supply is exhausted. Requests for additional copies will be considered upon further inquiry.

Reprint No.

61. Dissoultion Rates of Uranium Dioxide Sintered Pellets in Nitric Acid Systems by R. F. Taylor, Chemical Engineering Division, AERE, Harwell, England, E. W. Sharratt, Chemical Engineering Division, AERE, Harwell, England, L. E. M. de Chazal, Associate Professor Chemical Engineering and D. H. Logsdail, Chemical Engineering Division, AERE, Harwell, England. Reprinted from Journal of Applied Chemistry, Published by the Society of Chemical Industry, Volume 13, No. 1, January 1963, Pages 32-40.

62. Circuit Waveforms for Periodic Waves by D. L. Waidelich, Professor, Electrical Engineering, University of Missouri. Reprinted from Communication and Electronics, March 1963.

63. Transmission Losses and Economy Loading by the Use of Admittance Constants by J. R. Tudor, Associate Professor, Electrical Engineering, University of Missouri and W. A. Lewis, Research Professor, Electrical Engineering, Illinois Institute of Technology, Chicago, Illinois. Reprinted from Power Apparatus and Systems, IEEE, October, 1963.

64. Applicability of Thermoacoustic Phenomena to MHD Conversion Systems by R. L. Carter, Professor, Electrical Engineering, University of Missouri, K. T. Feldman, Jr., NDEA Fellow, Mechanical Engineering, University of Missouri, and C. N. McKinnon, Jr., Instructor, Mechanical Engineering, University of Missouri. Reprinted from Fifth Symposium of the Engineering Aspects of Magnetohydrodynamics MIT, April 1 \& 2, 1964.

65. Three and Four Coil Systems for Homogeneous Magnetic Fields by M. E. Pittman, Research Assistant, Physics Department, University of Maryland, D. L. Waidelich, Professor, Electrical Engineering, University of Missouri. Reprinted from IEEE Transactions on Aerospace, February, 1964.

66. Variable-Mesh Difference Equation for the Stream Function in Axially Symmetric Flow by J. C. Lysen, Associate Professor, Mechanical Engineering, University of Missouri. Reprinted from AIAA Journal, 1964.

67. Creep of Concrete: Influencing Factors and Prediction by A. M. Neville, Chairman, Division of Engineering, University of Alberta, Calgary, and B. L. Meyers, Assistant Professor of Civil Engineering, University of Missouri.

Effect of Creep and Shrinkage on the Behavior of Reinforced Concrete Members by A. Pauw, Professor and Chairman of Civil Engineering, and B. L. Meyers; Assistant Professor of Civil Engineering, University of Missouri. Reprinted from Symposium on Creep on Concrete, Publication SP-9, The American Concrete Institute.

68. A Method of Data List Processing with Application to EEG Analysis by C. M. Philpott, Control Data Corporation, St. Paul, Minnesota, and G. B. Lago, Professor of Electrical Engineering, University of Missouri. Reprinted from Communications of the ACM, Volume 8, Number 5, May, 1965.

69. Method for Obtaining the Trees of a v Vertex Complete Graph from the Trees of a v-1 Vertex Complete Graph by G. W. Zobrist, Assistant Professor of Electrical Engineering, University of Missouri, and G. V. Lago, Professor of Electrical Engineering, University of Missouri. Reprinted from the Matrix and Tensor Quarterly, Volume 15, Number 3, March, 1965.

70. Treatment of Livestock Waste-A Laboratory Study by E. A. Jeffrey, W. C. Blackmann, Jr., and Ralph Ricketts. Reprinted from Transactions of the ASAE, volume 8, number 1.

71. The Electronic Position Indicator by Richard P. Covert, Associate Professor of Industrial Engineering, University of Missouri. Reprinted from The Journal of Industrial Engineering, Volume XVI, No. 4, July-August, 1965, pages 255-259.

72. The Retlected Impedance of a Circular Coil in the Proximity of a Semi-Infinite Medium by David H. S. Cheng. Reprinted from IEEE Transactions on Instrumentation and Measurement, Volume IM-14, Number 3, September, 1965.

73. Irrotational Flow over Spillways of Finite Height by John J. Cassidy, Associate Professor of Civil Engineering, University of Missouri. Reprinted from The Journal of the Engineering Mechanics Division, Proceedings of the American Society of Civil Engineers, Volume 91, Number EM6, December, 1965. 


\section{The University of Missouri SCHOOLS AND COLLEGES}

For the Divisions at Columbia:

College of Agriculture

SCHOOL OF FORESTRY

SCHOOL OF HOME ECONOMICS

COllege of ARTS AND SCIENCE

SCHOOL OF SOCIAL WORK

SCHOOl of Business and Public Administration

COllege of EduCATION

COLLEGE OF ENGINEERING

ENGINEERING EXPERIMENT STATION

GRADUATE SCHOOL

SCHOOL OF JOURNALISM

SCHOOL OF LAW

SCHOOL OF MEDICINE

SCHOOL OF NURSING

UNIVERSITY EXTENSION DiVISION

SCHOOL OF VETERINARY MEDICINE

For THE Division AT ROLla:

SCHOOL OF Mines AND METALIURGY 
University of Missouri Libraries

University of Missouri

MU Engineering Experiment Station Series

Local Identifier Cassidy1965

Capture information

Date captured 2018 February

Scanner manufacturer Ricoh

Scanner model MP C4503

Scanning software

Optical resolution

$600 \mathrm{dpi}$

Color settings

File types

Grayscale, 8 bit; Color 24 bit Tiff

Source information

$\begin{array}{ll}\text { Format } & \text { Book } \\ \text { Content type } & \text { Text } \\ \text { Notes } & \begin{array}{l}\text { igitized duplicate copy not retained } \\ \text { in collection. }\end{array}\end{array}$

Derivatives - Access copy

Compression

Editing software

Resolution

Color

File types

Notes

\section{LZW}

Adobe Photoshop

600 dpi

Grayscale, 8 bit; Color, 24 bit

Tiffs converted to pdf

Greyscale pages cropped and canvassed. Noise removed from background and text darkened. Color pages cropped. 